\title{
UTILIZATION OF CITRUS MEDICA FOR THE REDUCTION OF NITRATE- NITROGEN FROM AQUEOUS SOLUTION
}

\author{
Mayilsamy,M., Santhiya,M., Swabna,V. and Vasanthy Muthunarayanan* \\ Department of Environmental Biotechnology, Bharathidasan University, Tiruchirappalli 620024, \\ Tamilnadu, India, \\ *vasanthy02@yahoo.co.in (Corresponding author) \\ Received on 26th July 2011, accepted in revised form 29th November 2011
}

\begin{abstract}
The objective of this study is to investigate the reduction of nitrate-nitrogen from aqueous nitrate-nitrogen solution containing $30 \mathrm{ppm}$ of nitrate-nitrogen using the leaves of Citrus medica in a powdered form. The reduction was found to be $85 \%$ from $30 \mathrm{ppm}$ nitrate-nitrogen containing solution. The mechanism of the reduction could be attributed to the antioxidant property of the Citrus medica leaves, which is found to be contributed by the flavonoids of the leaf material. This is confirmed by the DPPH activity of Citrus medica which signifies the $\mathrm{H}^{+}$ion donation to the nitrate-ions thereby facilitating reduction. The powdered leaves of Citrus medica were subjected to FT-IR analysis too which reveals certain changes in the peaks obtained for 2920 and $2855 \mathrm{~cm}^{-1}$.
\end{abstract}

(Keywords: Nitrate-nitrogen; Citrus medica; aqueous solution; Reduction; Antioxidant)

\section{INTRODUCTION}

Nitrate-nitrogen contaminations in surface and ground water have increased in many locations of the world. Although nitrate-nitrogen is found in moderate concentrations in most of the natural waters, higher levels in ground water mainly result from human and animal waste and excessive use of chemical fertilizers (Ying et al., 2002; Michal et al., 1995). The most common sources of nitrate-nitrogen are uncontrolled land discharges of municipal and industrial waste waters, overflowing septic tanks, processed food, dairy and meat products and decomposition of decaying organic matters buried in the ground (Sukru and Hatice, 2007; Mishra and Patel, 2009). Nitrates are reported to be extremely soluble in water and can move easily through soil into the drinking water supply (Mishra and Patel, 2009).

One of the most important environmental problem caused by nitrate-nitrogen is eutrophication in water supplies (Yu et al., 2007; Yunus et al., 2006; Hakan and Gul., 2010). Consumption of excess nitrate-nitrogen in drinking water cause blue baby syndrome called as Methaemoglobinemia in new born infants (Mishra and Patel, 2009; Yunus et al., 2006; Kei et al., 2004; Ayyasamy et al., 2009). Once consumed nitrate is converted to a very toxic substance (nitrite) by nitrate reducing bacteria in the human intestine, which reacts with the hemoglobin in blood converting it into methaemoglobin and altered form of blood protein prevents the blood cells from absorbing oxygen which leads to slow suffocation of the infant which may lead to death. Furthermore, nitrate can react with amines or amides in the body to form nitrosamine which is known to cause cancer (Sukru and Hatice, 2007).

Due to several health hazards caused by nitratenitrogen, certain conventional technologies have been developed for its reduction from drinking water, including distillation, reverse osmosis, ion exchange, electro dialysis, etc (Ayyasamy et al., 2009; Hakan and Gul., 2010). Biological treatment by microorganisms requires the supply of exogenous organic carbon and nutrients, which are seldom completely consumed. These nutrients remain in the treated water, causing 
secondary pollution and must be removed by extensive post treatment (Ayyasamy et al., 2009). The above mentioned nitrate-nitrogen reduction processes are relatively expensive. Therefore, inexpensive and simple operating processes are urgently required (Michal et al., 1995).

In recent years, considerable attention has been devoted to the study of different types of low cost materials such as tree bark, wood charcoal,

\section{MATERIALS AND METHOD}

\section{Preparation of low cost material}

The Citrus medica leaves was washed thoroughly with deionized water to remove dust and dirt. The washed raw material was dried at room temperature $\left(30^{\circ} \mathrm{C}\right)$. Further it was powdered, sieved (Sieve size was ASTM No: 250) and was stored in an air tight container.

\section{Preparation of aqueous solution}

All the glassware's used in the experiment was washed several times with deionized water. $\mathrm{KNO}_{3}$ is used as a source of nitrate-nitrogen. Stock solution of nitrate-nitrogen was prepared by dissolving $\mathrm{KNO}_{3}$ (dried at $205^{\circ} \mathrm{C}$ for 24 hours) in deionized water. Working solution containing $30 \mathrm{ppm}$ of nitrate-nitrogen was prepared from the stock nitrate solution.

\section{Nitrate-nitrogen reduction experiments}

Nitrate-nitrogen reduction experiments were performed with synthetic nitrate-nitrogen solution. In the first set of experiment, the effect of agitation was investigated by using a series of conical flasks containing $100 \mathrm{ml}$ of $30 \mathrm{ppm}$ aqueous nitrate-nitrogen solution. Different amounts of powdered Citrus medica (100, 300, 500 and $700 \mathrm{mg}$ ) was added and were subjected for continuous agitation for 2 hours followed by still condition. A control was maintained. The nitrate-nitrogen level in the synthetic solution was estimated every 6 hours until 36 hours. The concentration of nitrate-nitrogen was determined at $410 \mathrm{~nm}$ using a UV-Visible Spectrophotometer (Model: Systronics make) by the Brucine Sulphate method (APHA). This experiment was performed in triplicate. saw dust, alum sludge, red mud and other waste materials for reduction of some toxic substances (Yunus et al., 2006; Hakan and Gul., 2010).

The objective of this study was to examine the possibility of utilization of the low cost material such as powdered leaves of Citrus medica as an agent for the reduction of nitrate-nitrogen from aqueous nitrate-nitrogen containing solution.

Similar type of experiment was performed in still condition too, were the flasks were not given any agitation at all.

\section{Estimation of antioxidant activity of Citrus medica}

About 3ml of 1'-1'diphenylpicryl-hydrazyle (DPPH) was added to $100 \mu$ l of the sample and the sample was incubated for 30 minutes. The amount of antioxidant was determined before and after treatment using by UV-Visible Spectrophotometer (Model: Hitachi U-2001 make) (Paul et al., 2009).

\section{Analysis of Fourier Transform Infra Red Spectroscopy (FTIR)}

An infrared spectrum represents a finger print of a sample with absorption peaks which correspond to the frequencies of vibrations between the bonds of the atoms making up the material. The Citrus medica leaves were subjected for the FTIR (Model: Spectrum RXI) analysis for the identification of structural variations.

\section{Statistical analysis}

All experiments were conducted in triplicate, with the Citrus medica and the rate of nitratenitrogen reduction from both agitation and still condition was calculated. The experimental results obtained were subjected to the statistical analysis in terms of student's t-Test. 


\section{RESULTS AND DISCUSSION}

\section{Nitrate-nitrogen reduction from aqueous solution}

i)Effect of agitation on percentage of nitratenitrogen reduction effectiveness

The nitrate-nitrogen reduction efficiencies from the aqueous solution with leaves of Citrus medica are illustrated in Fig.1. The aqueous solution of $30 \mathrm{ppm}$ were subjected to nitratenitrogen reduction process by using four

different concentrations of powdered leaves of Citrus medica (100, 300, 500 and $700 \mathrm{mg}$ ) for about different time intervals $(0,6,12,18,24,30$ and 36 hours). Among the four concentrations of powdered leaves, $300 \mathrm{mg}$ shows the maximum reduction efficiency of $85 \%$ after 36 hours. In the control flask, the nitrate-nitrogen in the aqueous solution remained almost constant.

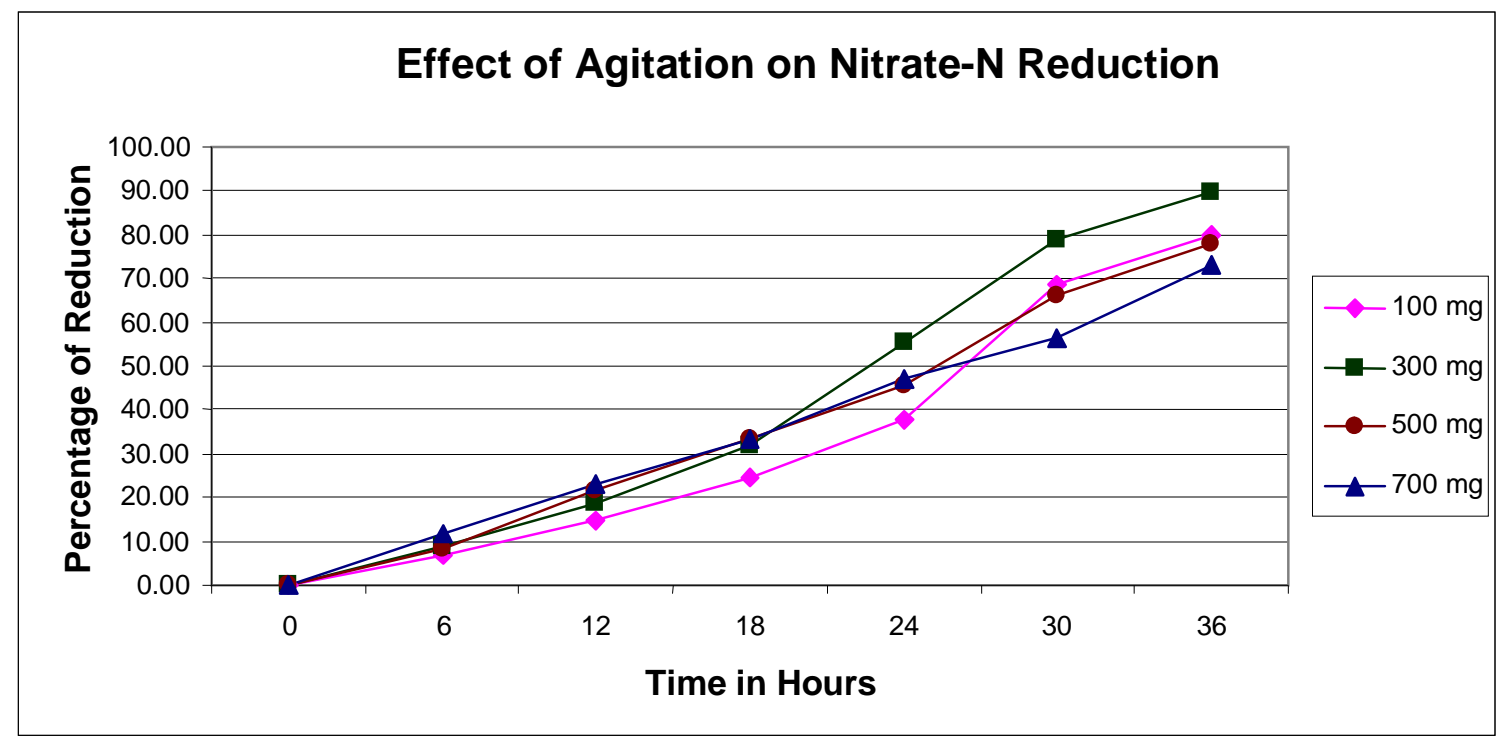

Figure 1. Effect of agitation on \% of nitrate-nitrogen reduction from aqueous solution.

ii) Effect of still condition on percentage of nitrate-nitrogen reduction effectiveness

The results obtained for similar type of experiments conducted, without agitation of the solution was obtained is illustrated in Figure 2. It was clear that the maximum efficiency of $85 \%$ after 48 hours. In all the control experiments, the nitrate-nitrogen concentration in the aqueous solution remained almost constant. 


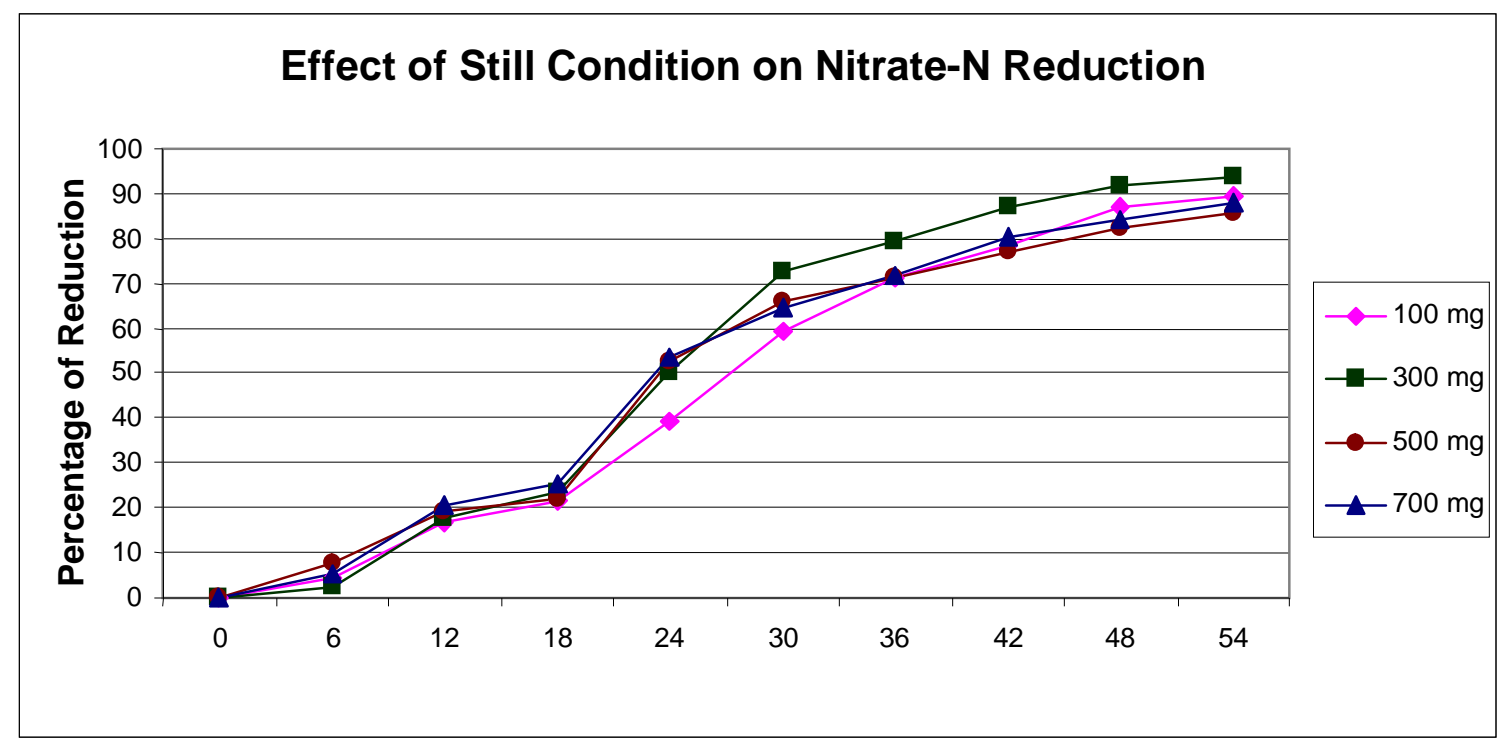

Figure 2. Effect of still condition on $\%$ of nitrate-nitrogen reduction from aqueous solution.

\section{Antioxidant activity analysis}

Earlier reports make us understand that the human diet contains important micronutrients, such as vitamin $\mathrm{C}$, vitamin $\mathrm{E}$, carotenoids and flavonoids, essential for maintenance of human health (Danila et al., 2005). Flavonoids are phenolic compounds which are called as secondary metabolites of plants. These compounds are widely distributed in the leaves, seeds, bark and flowers of plants. Over 4,000 flavonoids have been identified to date; such phenolic compounds have been reported to act as antioxidants by many potential pathways such as free radical-scavenging, oxygen radical absorbance, and chelating of metal ions (Kelly et al., 2002; Min-Sheng Su et al., 2008). These

\section{Estimation of antioxidant activity of Citrus medica leaves}

The maximum percentage of antioxidant activity before and after treatment with aqueous solution is illustrated in Fig.3. This suggests that the optimum initial concentration was $96.55 \%$ and phenolic groups serve as a source of a readily available "' $\mathrm{H}$ " atoms such that the subsequent radicals produced can be delocalized over the flavonoids structure (Danila et al., 2005). Citrus plants were found to be rich in naturallyoccurring flavonoids (Min-Sheng Su et al., 2008).

Antioxidants have much biological importance, at the same time the flavonoids induce the reduction of nitrate-nitrogen present in aqueous solution as they have significant antioxidant property and also act as a strong reducing agent.

after treatment the activity has declined to $37.50 \%$. It thus confirms the donation of $\mathrm{H}^{+}$ions to the nitrate-nitrogen reduction process. 

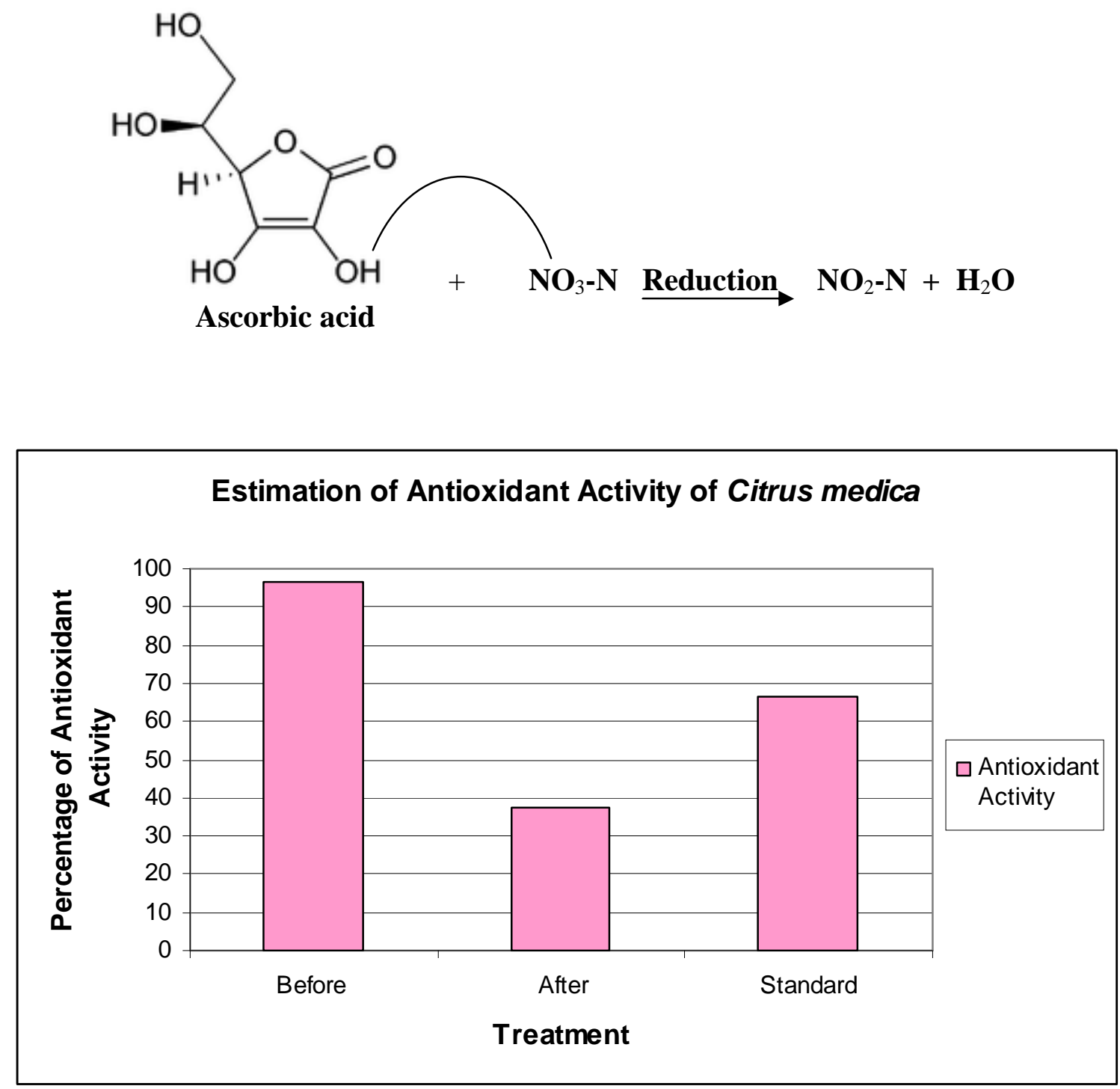

Figure 3. Estimation of antioxidant activity of powdered leaves of Citrus medica

\section{FTIR analysis}

Fourier transform infrared (FTIR) spectroscopy is a useful method for the deduction of changes in the chemical composition of the Citrus medica leaves, subjected for nitrate-nitrogen reduction.
Before treatment, the spectra has shown carbohydrate region that has a high intensity peak around 2920 and $2855 \mathrm{~cm}^{-1} 1$ due to aliphatic C-H stretching of $\mathrm{CH}_{2}$ group (Fig.4). 


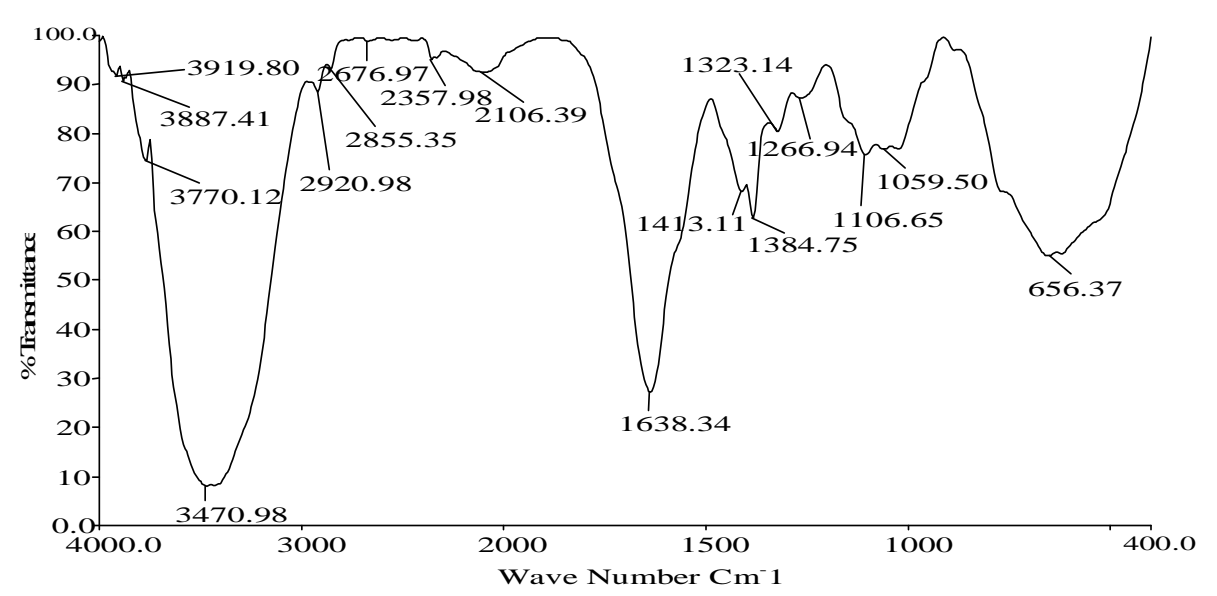

Figure 4. FT-IR spectra of Citrus medica leaves before treatment (Control)

The first significant change observed in leaf material after treatment with aqueous solution was the decrease in the intensity of peaks 2920 and $2855 \mathrm{~cm}^{-1}$ that could be attributed to significant degradation of lipids and carbohydrates are illustrated in Fig.5 (Zainab et al., 2009).

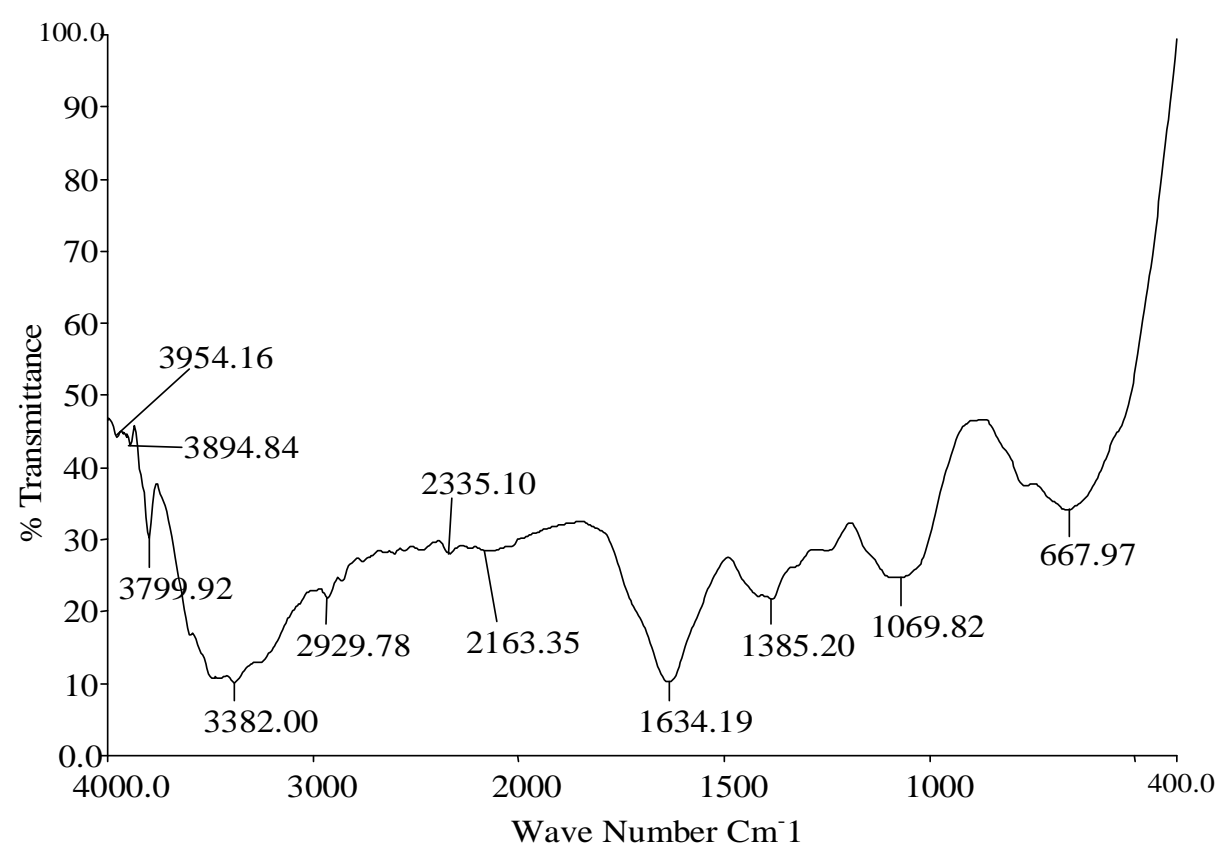

Figure 5. FT-IR spectra of Citrus medica leaves after treatment with aqueous solution 
The Citrus medica leaves were subjected for aqueous solution treatment depicts no considerable change in the wave number and the changes occur only in the intensity of peaks.

\section{Statistical analysis}

The results presented in Table $\mathbf{1}$ and $\mathbf{2}$. Shows a positive test between the different concentrations of Citrus medica leaves. We typically accept the significance with each t-test of 95\% ( $\mathrm{p}=0.05)$.
Thus the results clearly suggest the suitability of utilization of powdered leaves of Citrus medica for the nitrate-nitrogen reduction from aqueous solution.

The hypothesis set is that "The optimum dosage of Citrus medica leaves is $300 \mathrm{mg}$ for the treatment of $30 \mathrm{ppm}$ aqueous solution". This hypothesis has been accepted after the test.

Table 1. Effect of agitation on percentage of nitrate-nitrogen reduction from aqueous solution.

\begin{tabular}{|c|c|c|c|c|c|}
\hline S.No & $\begin{array}{c}\text { Concentration of } \\
\text { Citrus medica (mg) }\end{array}$ & F-Value & P-Value & df & Hypothesis \\
\hline 1 & 100 Vs 300 & 1.29246 & 0.7634 & 6,6 & Accepted \\
\hline 2 & 500 Vs 300 & 1.44755 & 0.6647 & 6,6 & Accepted \\
\hline 3 & 700 Vs 300 & 1.84309 & 0.4757 & 6,6 & Accepted \\
\hline
\end{tabular}

Table 2. Effect of still condition on percentage of nitrate-nitrogen reduction from aqueous solution.

\begin{tabular}{|c|c|c|c|c|c|}
\hline S.No & $\begin{array}{c}\text { Concentration of } \\
\text { Citrus medica }(\mathbf{m g})\end{array}$ & F-Value & P-Value & df & Hypothesis \\
\hline 1 & 100 Vs 300 & 1.18599 & 0.8036 & 9,9 & Accepted \\
\hline 2 & 500 Vs 300 & 1.31336 & 0.6913 & 9,9 & Accepted \\
\hline 3 & 700 Vs 300 & 1.26232 & 0.7342 & 9,9 & Accepted \\
\hline
\end{tabular}

\section{CONCLUSION}

In this study, the possibility of utilization of Citrus medica as an antioxidant for reduction of nitrate-nitrogen from aqueous solution, mainly consisting of $\mathrm{KNO}_{3}$ was investigated. It was concluded that the nitrate-nitrogen could be reduced when treated with $300 \mathrm{mg}$ of Citrus medica. The nitrate-nitrogen reduction efficiency from aqueous solution is about $85 \%$ after 36 
hours. The estimation of antioxidant activity of Citrus medica leaves before and after treatment with aqueous solution clearly confirms its capacity to donate $\mathrm{H}^{+}$ions for nitrate-nitrogen reduction process. The Citrus medica leaves could be of a great practical value for the

\section{ACKNOWLEDGEMENT}

We acknowledge the University Grants

Commission, New Delhi, India for the financial support provided to carry out the research work and also DST-FIST and UGC-NON SAP for the support

\section{REFERENCES}

1. American Public Health Association (APHA), 1998. Standard Methods for the Examination of Water and Wastewater. $20^{\text {th }}$ edition, Washington, DC, USA.

2. Ayyasamy, P.M., Rajakumar, S., Sathishkumar, M., Swaminathan, K., Shanthi, K., Lakshmanaperumalsamy, P., Lee, S., 2009. Nitrate removal from synthetic medium and groundwater with aquatic macrophytes. Desalination, 242, 286-296.

3. Danila, D.M., Marco, G., Maurizio, L.G., Elisa, T., Santo, G., Enrico, F., 2005. Flavanones in Citrus fruit: Structure-antioxidant activity relationships. Food Research International ,38, 1161-1166.

4. Hakan, D., Gul, G., 2010. Removal of nitrate from aqueous solutions by activated carbon prepared from sugar beet bagasse. Bioresource Technology ,101, 1675-1680.

5. Kei, M., Toshitatsu, M., Yasuo, H., Keiichi, N., Tomoki, N., 2004. Removal of nitrate-nitrogen from drinking water using bamboo powder charcoal. Bioresource Technology, 95, 255-257.

6. Kelly, E.H., Anthony R.T., Dennis J.B., 2002. Flavonoid antioxidants: chemistry, metabolism and structure-activity Relationships. Journal of Nutritional Biochemistry, 13, 572-584. technological application of nitrate-nitrogen reduction from aqueous solution. This method appears simple, reliable, cost effective and as a suitable treatment process for home water in rural areas of developing countries.
7. Michal, V., Shimshon, B., Aharon, A., Ines, M., Soares, M., 1996. Biological Denitrification of Drinking Water using Newspaper. Water Research, 30, 965971.

8. Min-Sheng, S., Yuan-Tay, S., Po-Jung, C., 2008. Antioxidant activities of citrus herbal product extracts. Food Chemistry, $111,892-896$.

9. Mishra, P.C., Patel, R.K., 2009. Use of agricultural waste for the removal of nitrate-nitrogen from aqueous medium. Journal of Environmental Management , 90, 519-522.

10. Paul, S., Saikia, J.P., Samdarshi, S.K., Konwar, B.K., 2009. Investigation of antioxidant property of iron oxide particles by 1-1 diphenylpicrylhydrazyle (DPPH) method. Journal of Magnetism and Magnetic Materials, 321, 3621-3623.

11. Sukru, A., Hatice, C., 2007. Biological denitrification of drinking water in a slow sand filter. Journal of Hazardous Materials, 148, 253-258.

12. Ying, F.L., Shuh, R.J., Tze, W.W., Der, Y.L., 2002. Effects of macrophytes and external carbon sources on nitrate removal from groundwater in constructed wetlands. Environmental Pollution, 119, 413-420.

13. Yu, W., Bao, Y.G., Wen, W.Y., Qin, Y.Y., 2007. Adsorption kinetics of 
nitrate from aqueous solutions onto modified wheat residue. Colloids and Surfaces A: Physicochem. Eng. Aspects, 308, 1-5.

14. Yunus, C., Ali, T., Mustafa, E., Gulsin, A., 2006. Removal of nitrate from aqueous solution by using red mud. Separation and Purification Technology, 51, 374-378.

15. Zainab, D., Valeria, D.O., Maria, R.P., Mohamed, H., Aaziz, O., 2009. Study of the biodegradation and transformation of olive-mill residues during composting using FTIR spectroscopy and differential scanning calorimetry. Journal of Hazardous Materials, 164, 1281-1285. 